\title{
Effect of Lipids and Other Substances on the Adsorption of Dipalmitoyl Phosphatidylcholine
}

\author{
C. MEBAN ${ }^{(23)}$ \\ Medical Biology Centre, The Queen's University of Belfast, Belfast, Northern Ireland
}

\begin{abstract}
Summary
The effect of various lipids, proteins, and other substances on the adsorption rate of dipalmitoyl phosphatidylcholine (DPC) was investigated. Each substance was added to a sonicated suspension of DPC in saline, and the surface pressure of the adsorbed surface film was measured using a platinum plate suspended from an electrobalance. Pure DPC adsorbed very slowly, being complete only after $8 \mathrm{hr}$; its half-adsorption time was $91.8 \pm 8.3 \mathrm{~min}$. Four additives markedly reduced the half-adsorption time of DPC: dipalmitoyl phosphatidylglycerol $(1.1 \pm 0.2 \mathrm{~min})$, phosphatidylinositol $(2.8 \pm 0.4 \mathrm{~min})$, serum high-density lipoprotein $(1.0 \pm 0.2$ min), and surfactant apoprotein $(0.9 \pm 0.1 \mathrm{~min})$. The half-adsorption times of mixtures of DPC and the other additives ranged from $15.3 \pm 1.9$ to $107.8 \pm 12.1 \mathrm{~min}$.
\end{abstract}

\section{Speculation}

The results suggest that dipalmitoyl phosphatidylglycerol, phosphatidylinositol, and serum high-density lipoprotein, in combination with dipalmitoyl phosphatidylcholine, may be of value in the treatment of respiratory distress syndrome in the human neonate.

It is now widely accepted that surfactant deficiency is a cardinal factor in the pathogenesis of respiratory distress syndrome of the human neonate $(1,7,16,17)$. Pediatricians are obviously anxious to develop a rational therapy for this condition. Indeed, attempts have already been made to introduce synthetic surface-active agents into the lungs of surfactant-deficient babies $(3,11)$, and experiments have been performed on the lungs of animals (69. $10,21)$. Of the agents tested so far, dipalmitoyl phosphatidylcholine (DPC) has produced the most promising results. Unfortunately, pure DPC only forms interfacial films at a very slow rate and, consequently, other substances have to be added to the DPC to accelerate its adsorption $(2,4)$.

The aim of the present study was to determine the effects of different additives on the adsorption of DPC.

\section{MATERIALS AND METHODS}

Surfactant was removed from the lungs of neonatal lambs using the technique described previously (14). Lipids and apoprotein were isolated from the surfactant by the method of Scanu et al. (19). Human serum high-density lipoprotein, bronchial mucoprotein, and salivary mucoprotein were kindly provided by $\mathrm{Dr} S$. McCaughey of The Queen's University of Belfast. The other chemicals were purchased from Sigma London Chemical Company. Double-glass distilled water was used to prepare the solutions.

\section{PREPARATION OF SOLUTIONS}

The solutions of DPC and other materials in saline $(0.145 \mathrm{M}$ $\mathrm{NaCl}$ ) were prepared in the concentrations indicated in Tables 1 to 3 . Each solution was sonicated in a water bath at $0^{\circ} \mathrm{C}$ until it was opalescent (about $5 \mathrm{~min}$ ) and then heated to $37^{\circ} \mathrm{C}$ before use.

\section{ADSORPTION MEASUREMENTS}

Thirty $\mathrm{ml}$ of each solution was placed in a circular glass dish (cross-sectional area, $36.5 \mathrm{~cm}^{2}$ ). The surface tension of the adsorbed film was measured using a platinum dipping plate (perimeter, $8.4 \mathrm{~cm}$ ). The plate was suspended from a Cahn electrobalance, and the strain was recorded on an Anadex printer. The sensitivity of the apparatus was about $0.1 \mathrm{mN} / \mathrm{m}$. The glass dish was placed in a water bath and maintained at $37^{\circ} \mathrm{C}$ throughout the experiment. The surface pressure $(\pi)$ of each film was calculated using the relationship

$$
\pi=\gamma_{0}-\gamma
$$

where $\gamma_{0}$ and $\gamma$ are the respective surface tensions of the clean and film-covered surfaces. All measurements were made under static conditions; consequently, the surface pressure generated by the films was lower than that achieved in dynamic compression experiments.

The change in the surface pressure of the adsorbed films was recorded for a variable length of time $(30 \mathrm{~min}$ to $6 \mathrm{hr}$ ) and also after an interval of $24 \mathrm{hr}$. The pressure generated by a film after aging for $24 \mathrm{hr}$ is referred to as the "maximum film pressure." The half-adsorption time of each film was obtained from the plot of surface pressure against time. This was the time in which $50 \%$ of the final total change in surface pressure was achieved.

\section{RESULTS}

An example of the changes in the surface pressure of adsorbed films with age is shown in Figure 1. Pure DPC adsorbed slowly (half-adsorption time, $91.8 \pm 8.3 \mathrm{~min}$ ), and hence, the pressure at the subphase surface increased gradually. In contrast, a mixture of DPC and phosphatidylinositol (9:1 molar ratio) adsorbed relatively rapidly.

The data relating to the adsorption of mixtures of DPC and various additives are given in Tables 1 and 2 . Inspection of the data shows that many of the additives had little effect on the adsorption rate of DPC. Only mixtures containing dipalmitoyl phosphatidylglycerol, phosphatidylinositol, serum high-density lipoprotein, and surfactant apoprotein had half-adsorption times of less than $10 \mathrm{~min}$.

The effects of dipalmitoyl phosphatidylglycerol, phosphatidylinositol, and serum high-density lipoprotein on the adsorption rate of DPC varied with concentration (Table 3). Both dipalmitoyl phosphatidylglycerol and phosphatidylinositol decreased progressively in activity as their concentration was reduced over the range 12.8 to $0.8 \mu \mathrm{g} / \mathrm{ml}$. In contrast, the activity of high-density lipoprotein fell sharply (reflected in the marked increase of the halfadsorption time) when its concentration was reduced below 12.8 $\mu \mathrm{g} / \mathrm{ml}$. 
Table 1. Effects of various lipid additives on the adsorption of $D P C^{1}$

\begin{tabular}{lccc}
\hline \multicolumn{1}{c}{ Additive } & $\begin{array}{c}\text { Additive/DPC } \\
\text { molar ratio }\end{array}$ & $\begin{array}{c}\text { Half-adsorption } \\
\text { time of DPC (min) }\end{array}$ & $\begin{array}{c}\text { Maximum surface pressure } \\
\text { of adsorbed film (mN/m) }\end{array}$ \\
\hline Distearoyl phosphatidylcholine & $1: 9$ & $106.5 \pm 10.7^{2}$ & $34.8 \pm 2.9$ \\
Diheptadecanoyl phosphatidylcholine & $1: 9$ & $96.3 \pm 8.8$ & $36.0 \pm 2.7$ \\
Dimyristoyl phosphatidylcholine & $1: 9$ & $93.9 \pm 11.2$ & $35.6 \pm 3.1$ \\
Dilauroyl phosphatidylcholine & $1: 9$ & $84.6 \pm 7.4$ & $34.7 \pm 2.3$ \\
Phosphatidylcholine (unsaturated, egg) & $1: 9$ & $94.0 \pm 9.9$ & $35.3 \pm 2.4$ \\
Dipalmitoyl phosphatidylethanolamine & $1: 19$ & $93.8 \pm 8.7$ & $33.9 \pm 2.1$ \\
Dipalmitoyl phosphatidyldimethylethanolamine & $1: 19$ & $100.9 \pm 10.3$ & $35.0 \pm 2.8$ \\
Dipalmitoyl phosphatidylglycerol & $1: 9$ & $1.1 \pm 0.2$ & $35.8 \pm 2.7$ \\
Phosphatidylinositol & $1: 9$ & $2.8 \pm 0.4$ & $34.9 \pm 2.4$ \\
Sphingomyelin & $1: 9$ & $86.3 \pm 6.8$ & $35.1 \pm 2.7$ \\
Tripalmitin & $1: 79$ & $92.8 \pm 8.5$ & $35.2 \pm 2.5$ \\
Cholesterol palmitate & $1: 9$ & $45.7 \pm 4.0$ & $34.0 \pm 2.6$ \\
Cholesterol & $1: 79$ & $85.9 \pm 7.9$ & $34.5 \pm 3.1$ \\
DPC (without additive) & & $91.8 \pm 8.3$ & $35.6 \pm 2.6$ \\
\hline
\end{tabular}

${ }^{1}$ The surface pressure of the films is expressed in units of millinewtons per meter (mN/m). Concentration of DPC is $200 \mu \mathrm{g} / \mathrm{ml}$ in each mixture.

${ }^{2}$ Mean \pm S.E. of measurements on 10 films.

Table 2. Effects of various additives on the adsorption of $D P C^{1}$

\begin{tabular}{lcc}
\hline \multicolumn{1}{c}{ Additive } & $\begin{array}{c}\text { Half-adsorption } \\
\text { time of DPC (min) }\end{array}$ & $\begin{array}{c}\text { Maximum surface pressure } \\
\text { of adsorbed film (mN/m) }\end{array}$ \\
\hline Glycerol & $94.9 \pm 9.8^{2}$ & $34.8 \pm 2.9$ \\
Dextran (molecular weight, 111,000) & $96.6 \pm 10.7$ & $35.6 \pm 3.0$ \\
Glucosamine HCl & $92.3 \pm 11.3$ & $35.3 \pm 2.7$ \\
Polyalanine (molecular weight, 10,000-25,000) & $89.7 \pm 9.8$ & $35.5 \pm 2.3$ \\
Polyglutamic acid (molecular weight, 50,000-100,000) & $76.2 \pm 7.0$ & $34.9 \pm 2.1$ \\
Serum albumin (human) & $76.8 \pm 6.4$ & $30.1 \pm 1.9$ \\
Serum globulins (bovine) & $89.5 \pm 8.1$ & $32.4 \pm 2.0$ \\
Serum high density lipoprotein (human) & $1.0 \pm 0.2$ & $35.8 \pm 2.6$ \\
Bronchial mucoprotein (human) & $46.3 \pm 3.6$ & $33.9 \pm 2.2$ \\
Salivary mucoprotein (human) & $30.1 \pm 4.3$ & $33.8 \pm 2.4$ \\
Whole surfactant (ovine) & $15.3 \pm 1.9$ & $35.7 \pm 2.8$ \\
Surfactant lipids (ovine) & $34.3 \pm 4.7$ & $35.6 \pm 2.5$ \\
Surfactant apoprotein (ovine) & $0.9 \pm 0.1$ & $34.5 \pm 2.7$ \\
DPC (without additive) & $91.8 \pm 8.3$ & $35.6 \pm 2.6$ \\
\hline
\end{tabular}

${ }^{1}$ Concentration of additives $20 \mu \mathrm{g} / \mathrm{ml}$. The surface pressure of the films is expressed in millinewtons per meter $(\mathrm{mN} / \mathrm{m})$.

${ }^{2}$ Mean \pm S.E. of measurements on 10 films.

Table 3. Effects of various additives on the adsorption of $D P C^{1}$

\begin{tabular}{|c|c|c|c|}
\hline \multirow[b]{2}{*}{$\begin{array}{c}\text { Concentration } \\
\text { of } \\
\text { additive }(\mu \mathrm{g} / \\
\text { ml) }\end{array}$} & \multicolumn{3}{|c|}{ Half-adsorption time of DPC (min) } \\
\hline & $\begin{array}{c}\text { Phosphatidyl- } \\
\text { inositol }\end{array}$ & $\begin{array}{c}\text { Dipalmitoyl- } \\
\text { phosphatidylglycerol }\end{array}$ & $\begin{array}{l}\text { High-den- } \\
\text { sity } \\
\text { lipoprotein }\end{array}$ \\
\hline 25.6 & $3.5 \pm 0.3^{2}$ & $1.0 \pm 0.2$ & $1.1 \pm 0.2$ \\
\hline 12.8 & $3.1 \pm 0.2$ & $2.1 \pm 0.1$ & $0.9 \pm 0.2$ \\
\hline 6.4 & $10.7 \pm 1.0$ & $22.8 \pm 2.0$ & $77.3 \pm 6.8$ \\
\hline 3.2 & $29.4 \pm 4.1$ & $37.5 \pm 5.2$ & $90.7 \pm 8.7$ \\
\hline 1.6 & $62.2 \pm 6.7$ & $82.9 \pm 7.9$ & $89.3 \pm 8.5$ \\
\hline 0.8 & $75.0 \pm 6.9$ & $93.7 \pm 8.6$ & $92.4 \pm 10.2$ \\
\hline
\end{tabular}

${ }^{1}$ Concentration of DPC is $200 \mu \mathrm{g} / \mathrm{ml}$ in each mixture. The half-adsorption time of pure DPC was $91.8 \pm 8.3 \mathrm{~min}$.

${ }^{2}$ Mean \pm S.E. of measurements on eight films.

\section{DISCUSSION}

The results of the present study have shown that pure DPC adsorbs very slowly to form films at air-fluid interfaces; maximum adsorption was only achieved from a saline subphase at body temperature after $8 \mathrm{hr}$. Although DPC is the most abundant of the lipids in natural pulmonary surfactant $(8,12,20)$, it is unlikely to be of much value if used on its own in the treatment of surfactant-deficient babies.

The adsorption of surface-active materials is a complex phenomenon. The rate at which molecules of two or more surface-

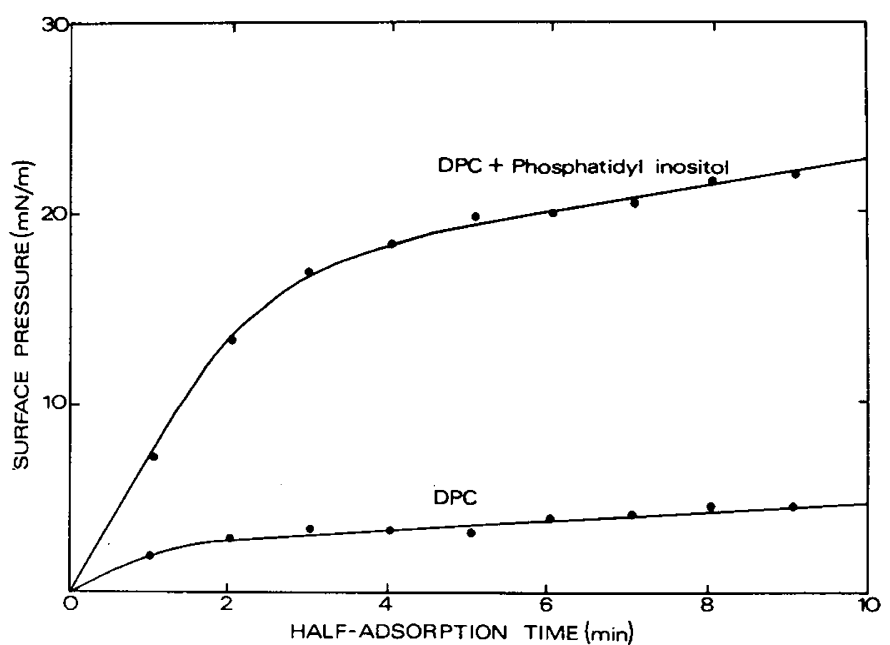

Fig. 1. Adsorption kinetics of pure DPC and a mixture of DPC and phosphatidylinositol (9:1 molar ratio) from saline at $37^{\circ} \mathrm{C}$. The surface pressure of the adsorbed films is expressed in units of millinewtons per meter $(\mathrm{mN} / \mathrm{m})$.

active agents accumulate at the free surface of a solution depends principally on the concentration of the agents, the nature of the amphiphilic groups in the agents and the separation of these groups (chain length), the nature of the molecular interaction 
between the agents, the diffusion coefficient of the solution, and the temperature $(5,15)$. It is obvious, therefore, that the measurements made in the present study do not permit the calculation of absolute adsorption coefficients. On the other hand, the measurements do indicate the relative rates of adsorption of the various substances under controlled conditions in vitro.

Of the different additives tested, dipalmitoyl phosphatidylglycerol, phosphatidylinositol, serum high-density lipoprotein, and surfactant apoprotein were most effective in accelerating the adsorption of DPC. It is interesting to note in this context that DPC has been used to treat babies suffering from respiratory distress syndrome. Chu et al. (3) have found that the inhalation of an aerosol of DPC in a Freon propellant caused a slight increase in the compliance of the babies' lungs, but no change in pulmonary blood flow or gas exchange. Ivey et al. (11) have reported that the arterial blood of premature babies was better oxygenated after the administration of a nebulized mixture of DPC and dipalmitoyl phosphatidylglycerol (9:1 molar ratio), whereas recent experiments (10) using surfactant-depleted lungs in vitro have shown that mixtures of DPC and unsaturated phosphatidylglycerol or phosphatidylinositol produce a significant increase in the total pulmonary capacity. King et al. (13) have demonstrated that the apoprotein moiety of canine surfactant accelerates the adsorption of the phospholipid moiety. This apoprotein has a relatively low molecular weight (about 10,700); in addition, it has an unusually large proportion of hydrophobic amino acids.

Serum high-density lipoprotein clearly deserves further attention. It is capable of accelerating the adsorption of DPC when present in concentrations of $12.8 \mu \mathrm{g} / \mathrm{ml}$ or more, and the resulting films generate a relatively high surface pressure under static conditions $(35.8 \mathrm{mN} / \mathrm{m})$. Serum lipoproteins have a carrier role in the body, the protein-binding lipid for the purpose of transporting it from one place to another. Because these molecules have weak bonding, the lipid moiety is easily displaced or replaced (18). Furthermore, high-density lipoprotein can be extracted from homologous human serum in a relatively pure form and, consequently, it is unlikely to provoke an immune reaction if administered in vivo.

\section{REFERENCES AND NOTES}

I. Avery, M. E., and Mead, J.: Surface properties in relation to atelectasis and hyaline membrane disease. Am. J. Dis. Child., 97: 517 (1959).

2. Bangham, A. D., Morley, C. J., and Phillips, M. C.: The physical properties of an effective lung surfactant. Biochim. Biophys. Acta, 573: 552 (1979).

3. Chu, J., Clements, J. A., Cotton, F. K., Klaus, M. H., Sweet, A. Y., and Tooley, W. H.: Neonatal pulmonary ischemia. Pediatrics, 40: 709 (1967).

4. Clements, J. A.: Composition and properties of pulmonary surfactant. In: C. E. Villee, D. B. Villee, J. Zuckerman: Respiratory Distress Syndrome. p. 77-98 (Academic Press, Inc., New York, 1973).

5. Davies, J. T., and Rideal, K. E.: Interfacial Phenomena. Ed. 2, pp. 154-216 (Academic Press, Inc., New York, 1963).

6. Enhorning, G., and Robertson, B.: Lung expansion in the premature rabbit fetus after tracheal deposition of surfactant. Pediatrics, 50: 8 (1972).

7. Farrell, P. M., and Avery, M. E.: Hyaline membrane disease. Am. Rev. Respir. Dis., 111: 657 (1975).

8. Fronsolono, M. F., Charms, B. L., Pawlowski, R., and Slivka, S.: Isolation, characterization, and surface chemistry of a surface-active fraction from dog lung. J. Lipid Res., 11: 439 (1970).

9. Ikegami, M., Hesterberg, T., Nozaki, M., and Adams, F. H.: Restoration of lung pressure-volume characteristics with surfactant. Comparison of nebulization versus instillation and natural versus synthetic surfactant. Pediatr. Res., 11: 178 (1977).

10. Ikegami, M., Silverman, J., and Adams, F. H.: Restoration of lung pressurevolume characteristics with various phospholipids. Pediatr. Res., 13:777 (1979).

11. Ivey, H., Roth, R., and Kattwinkel, M.: Nebulization of sonicated phospholipids for treatment of respiratory distress syndrome of infancy. Pediatr. Res., 11:573 (1977).

12. King, R. J., and Clements, J. A.: Surface active materials from dog lung. II. Composition and physiological correlations. Am. J. Physiol., 223: 715 (1972).

13. King, R. J., Klass, D. J., Gikas, E. G., and Clements, J. A.: Isolation of apoproteins from canine surface-active materials. Am. J. Physiol., 224: 788 (1973).

14. Meban, C.: Surface elastic properties of surfactant from the lungs of neonatal pigs. Biol. Neonate, 37: 308 (1980)

15. Moilliet, J. L., Collie, B., and Black, W.: Surface Activity. Ed. 2, pp. 64-131 (Spon, London, 1961).

16. Nelson, N. M.: Biochemical lesions in respiratory distress syndrome. In: C. E. Villee, D. B. Villee, J. Zuckerman: Respiratory Distress Syndrome. p. 129 (Academic Press, Inc., New York, 1973).

17. Reynolds, E. O. R., Orzalesi, M. M., Motoyami, E. K., Craig, J. M., and Cook, C. D.: Surface properties of saline extracts from lungs of newborn infants. Acta Paediatr. Scand., 54: 511 (1965).

18. Scanu, A. M.: Structural studies on serum lipoproteins. Biochim. Biophys. Acta, 265: 471 (1972).

19. Scanu, A., Pollard, H., Hirz, R., and Kothary, K.: On the conformational instability of human serum low-density lipoprotein: effect of temperature. Proc. Natl. Acad. Sci. U. S. A., 62: 171 (1969).

20. Scarpelli, E. M., Clutario, B. C. and Taylor, F. A.: Preliminary identification of the lung surfactant system. J. Appl. Physiol., 23: 880 (1967).

21. Shannon, D. C., Kazemi, H., Merril, E. W., Smith, K. A., and Wong, P. S. L.: Restoration of volume-pressure curves with lecithin fog. J. Appl. Physiol., 28: 470 (1970).

22. The author thanks Ann Richardson for typing the manuscript.

23. Requests for reprints should be addressed to: C. Meban, B.Sc., M.D., Ph.D., Medical Biology Centre, 97 Lisburn Road, Belfast, BT9 7BL, Northern Ireland. 24. Received for publication July 15, 1980.

25. Accepted for publication September 12, 1980. 